\title{
The Impact of Social Support on EFL Learners' Motivation at Iraqi Kurdistan Universities
}

\author{
Mohamad Yahya Abdullah ${ }^{1} \&$ Khaldoon Waleed Husam Al-Mofti ${ }^{2}$ \\ ${ }^{1}$ English Department, Al Buraimi University College, Oman \\ ${ }^{2}$ English Department, Faculty of Arts, Anbar University, Iraq \\ Correspondence: Mohamad Yahya Abdullah, Al Buraimi University College, P.O. Box 77: Code 512, Al Buraimi, \\ Sultanate of Oman. Tel: 968-9435-7576. E-mail: Abdullah@buc.edu.om
}

Received: December 29, 2016

Accepted: February 19, 2017

Online Published: June 9, 2017

doi:10.5539/mas.v11n $7 \mathrm{p} 51$

URL: https://doi.org/10.5539/mas.v11n7p51

\begin{abstract}
There are many reasons standing behind the fact why non-native speakers study English as a foreign language. For some, the aspiration to be a foreign language teacher or the ability to use English at work is the main reasons and driving factors, while for others the reason is simply to pass the course requirement at schools and universities. The present study aims to evaluate student motivation level and the factors influencing motivation. This paper will also highlight the influence of the factor of social support on the other factors of motivation. Data were gathered through likert scale questionnaires distributed to EFL learners of English in two different universities in Kurdistan region of Iraq and semi-structured interviews conducted with a number of students who have been selected randomly. The results indicated that the motivation to learn English is not dominated by one factor; however, the factors of goals, intention, and outside social support appear as the most influenced factors. Also, there was a statistically significant parallel correlation between the outside social support and goals factors. Consequently, the outside social factor appears as a significant contributor to the motivation of EFL Kurdish learners.
\end{abstract}

Keywords: EFL Kurdish learners, motivation, English Language learning

\section{Introduction}

\subsection{Background of the Study}

There are many reasons standing behind the fact why non-native speakers study English as a foreign language. For some, the aspiration to be a foreign language teacher or the ability to use English at work are the main reasons and driving factors, while for others the joy of learning a new language and the gaining of the sense of personal achievement are the influencing elements (Crystal, 2003). However, for many students, the reason is simply to pass the course requirement at schools and universities, which brings up the issue of motivation to master a foreign language.

Poor teaching materials and instructions are many times being the reasons standing behind poor grasp of linguistic knowledge and performance (Chu Ying, \& Young, 2007), but they are not the sole and direct causes. Besides instructional materials, teachers' role to foster students' use of second language inside and outside the classroom and the students' willingness or intrinsic state to use the second language are essential in the mastery of the second language (Pardo \& Téllez, 2009). The latter develops in students while they learn to address gaps in knowledge. It is nourished by an aggregate of stimuli from different factors, including the psycho-social environment the learners live in. This internal state and the processes which lead to it are collectively called motivation (Do“rnyei, 1994).

Motivation is both the attitude needed to achieve a desired goal and the processes which develop and sustain the attitude. In-classroom factors which affect motivation include quality instruction, input, lack of pairs or group work, negation, embarrassment, and timing, whereas out-of-classroom factors include lack of opportunities to practice speaking with native English speakers. These aspects of learning process need to be taken into consideration to increase and maintain motivation for language learning (Kirova et al, 2012). Schmidt et al (1996) emphasize on the strong relationship between communicative classes and high level of motivation. According to them, if the target language is used for communication both inside and outside the classroom, motivation should 
be promoted spontaneously.

Whatever the motivation of learning English, people utilize different resources to master the language. In countries, such as Iraq, where English is rarely used as a first means of communication and its use is limited to academic settings, language learners including school and university students often utilize non-academic resources, such as mass media, informal face-to-face conversation with tourists, and interaction with foreign workers, including foreign military presence, to improve their English.

Although English is taught in all levels of education in Iraq, where the language is rarely used as the first means of communication and is mostly limited to academic settings, students suffer from low level of motivation to master the language (Rabab'ah, 2001 \& Keong \& Mussa, 2015). The case is common even among university students who have chosen to specialize in English. Reasons for it could be both classroom based or internal factors, which deal with teaching and academic resources, as well as non-classroom based or external factors, such as lack of social interaction or lack of family and societal support to learn English. If Iraq wants to improve the English language proficiency of its college youths, investigating the reasons for low motivation and exploring means to increase motivation levels and learning processes is utmost necessary.

\subsection{Purpose of the Study}

The present study tries to evaluate student motivation level and factors influencing motivation by using questionnaire distributed to EFL learners of English in two different universities in Kurdistan region of Iraq. The results are expected to fill the gap in knowledge about factors that affect motivation levels among the Kurdish learners. This study is the first to tackle the motivation issue among university students in Iraq. Though, the focus of the study are Kurdish university students, who have better access to non-academic resources for English language learning, such as access to social interaction with English speaking tourists and business personals, than students from other parts of Iraq. The results of the study will help to demonstrate the level of motivation in learning English, raise awareness about demotivated students, and provide direction for future studies involving students from other parts of Iraq.

For this purpose, the following questions are addressed in the current study:

1) What is the most effective factor of motivation for Kurdish EFL students?

2) To what extent, the motivation component of social support affects Kurdish students`motivation? And how is this different than other factors of motivation?

\section{Literature Review}

\subsection{Theoretical Framework}

Within the area of L2 learning process, there are many factors that impact students' efficiency and productivity (Lee, 2005). One of the most important factors influencing success or failure is motivation (Cheng \& Dörnyei, 2007). There is a general consensus among different scholars about the central role of motivation in the field of learning English as a second and foreign language (Dörnyei, 1990, Crookes \& Schmidt 1991; Dörnyei 1994; Cheng \& Dörnyei, 2007; Williams \& Williams, 2011; Phan, 2010). They have stated its fundamental function in associating progressing learning situation. Moreover, they have indicated that motivation is a variable which is stimulated by others whether the students are inside or outside the classroom.

There are several different theories and models from earlier studies that explain the role of motivation in learning English as a second language. . In 1978, Schumann in his acculturation theory stated that social and affective factors, such as adoption of foreign culture, personality, and motivation considerably influence the level of competency in the second and foreign language learning. In 1980, Clement in his social context model stated that motivation determines the level of L2 competence attained by learners. In 1981, Carroll proposed reinforcement model in which habit formation forms the effective motivating resource to facilitate language learning. Later in 1982, Krashen in Monitor Theory looked at emotional factors and motivation as key elements which together form a filter to control mental processes related to language learning, and hence affect degree of language acquisition., While these models emphasized association between motivation and social factors in language acquisition, Crookes and Schmidt (1991) conceptualised a model where motivation is related to L2 learning on four different levels, which are:

1) Microlevel, where there is an association between attention and motivation, with highly motivated L2 students showing greater attention.

2) Classroom level, where events inside classrooms play a key role on students' motivation. The events could be classroom tasks, teaching methods, amount of interaction between teachers and students as well as 
between students. Those events which match students' needs produce motivated students, who in term do better in language acquisition.

3) Curricular level, where the use of communicative approach to fulfil learners' needs are associated with motivation, with programs that satisfy students' perception and expectation being highly motivating.

4) Long-term learning outside the classroom; where opportunities for L2 learners to practice the language outside the classroom is associated with motivation and hence to language acquisition.

Because of its situated nature, the Model of Crookes and Schmidt is used to create the conceptual framework of this study.

\subsection{Past Studies}

Several studies have investigated the interrelationship between motivation and L2 learning process. Results of these studies show a variable relationship between motivation and L2 competency (Cheng \& Dörnyei, 2007), which can be attributed to different educational backgrounds, cultures, materials, and teaching methods. According to Williams, K.C. \& Williams, C.C (2011:1) in Five Key Ingredient for Improving Student Motivation, motivation in classroom is a function of five components which are student, teacher, content, method, and environment. Aspects of these components can contribute to or hinder motivation. In a study by Bahous et al (2011) at Lebanese American University, teachers' views and students' perceptions towards an EFL program were examined for demotivating factors among EFL students. The results showed that unprompted materials, incoherent relation between students' majors and language courses as well as focus on one skill such writing over others were taken as impediments towards learning by students. However, the same study also found that students' perceptions of demotivating factors are different from that of teachers, who complained of unenthusiastic students and the lack of opportunities to use communicative methods in classroom as reasons keeping students from mastering the language.

The relationship between teachers' awareness of use of communicative techniques and students' motivation was examined by Noels in 2001, in which a significant relationship between the two was found. In addition, the study found a remarkable correlation between students' intrinsic motivation and integrative orientation, which is promoted through independent learning, praise and encouragement, and positive feedback provided in an uncritical manner. The latter is supported by a study conducted by Hashimoto (2002), which uses socio-educational model and willingness to communicate (WTC) to investigate a set of variables which impact the frequency of L2 use inside the classroom. The results show that promoting willingness to communicate and raising the perceived competency positively affect the frequency of use of L2 in the classroom, and creating a less threatening environment of learning decreases anxiety and increases the motivation to use L2 inside the classroom.

In terms of the impact of social support on the L2 motivation, a study by Vatankhah and Tanbakooei (2014) involving of 60 intermediate Iranian level EFL male and female students showed a positive effect of social support such as parents, siblings and EFL teachers on L2 learners' motivation. The authors concluded that skilful L2 learners are typically those who have been motivated intrinsically and extrinsically to learn English, and hence to increase motivation of students, all social support factors should be promoted.

In another study of EFL learners, Phan (2010) adopted the self-determination theory to study factors affecting motivation in Vietnamese technical English majors. The results showed that the EFL learners were more motivated when teachers provided them with assignments and activities associated with the real world. Outside the classroom, the students were intrinsically motivated to accomplish tasks considered part of their needs and interests. When students assimilated English culture into their own through products and media, it powerfully impacted their motivation. And, as much as the teachers' support played a key role in motivating students to learn English, family members, especially parents, had a considerable role in enhancing learners' motivation.

Despite all the efforts in examining motivation behind L2 learning, research results are not generalizable, and many studies do not provide strategies for pedagogical improvement. Moreover, there are no experimental studies on Iraqi Kurdish English learners to explore the factors that motivate them to learn English. Therefore, this study aims to examine the factors that motivate Kurdish EFL learners using the conceptual framework of Crookes and Schmidt (1991) model.

\section{Methodology}

\subsection{Data collection}

The participants comprised 60 students from English departments of two different universities in the Kurdistan region. All were third year students representing the intermediate level of learning English at universities in 
Kurdistan. A questionnaire has been developed to explore the most effective factors of motivation for Kurdish EFL students as well as the impact of the motivation component of social support on other motivation factors. The questions covered four different factors for motivation, namely those related to the student, the classroom, the social factor, and outside the social factor. The students were asked to indicate their opinion after each statement by circling a number between 1and 4, with 1 being strongly agree and 4 being strongly disagree, that best described the extent to which they believed the statement applied to them (see Appendix I). Besides the questionnaire, semi-structured interviews have been conducted randomly on a sample of nine of the participants to enrich data and cross validate the students' responses to the questionnaire.

\subsection{Data Analysis}

The quantitative data from the questionnaire were analyzed in terms of means using the Statistical Package for Social Sciences (SPSS) 15.0 and percentage. First, Cronbach's alpha was calculated to test the internal consistency of the motivating factors. Second, the means of each motivational factor were also calculated to show the levels of their significant impact. Following this, the relation between the social support factor and other factors of motivation was tested by means of Pearson correlation. Finally, the content analysis method was used to analyze the qualitative data. Thus, the interviewees' responses for each question were analyzed in terms of themes related to the research objectives.

\section{Results and Discussion}

Table 1 shows questionnaire reliability analysis which measured by Cronbach's Alpha. It achieved a high reliability score of .98. It indicated the internal consistency and homogeneity of questionnaire items.

Table 1. Questionnaire's Reliability

\begin{tabular}{ccc}
\hline & \multicolumn{2}{c}{ Reliability Statistics } \\
\hline $\begin{array}{c}\text { Cronbach's Alpha } \\
.989\end{array}$ & Cronbach's Alpha Based on Standardized Items & N of Items \\
\hline
\end{tabular}

Figure 1 summarizes the frequencies of the factors affecting the motivation of Kurdish learners of English in terms of frequencies. The factors investigated were student intentions, goals, disposition, activities, classroom interaction, social family and outside social. The frequencies are also presented in terms of a bar diagram in Figure 1.

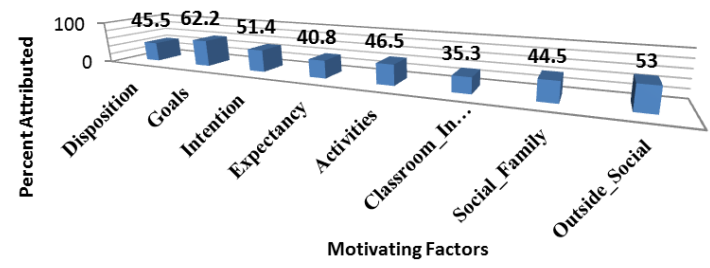

Figure 1. Bar Diagram of Factors Motivating Kurdish Students to Learn English

The results in Figure 1 clearly show that for the Kurdish students, the motivation to learn English is not dominated by a single factor. Of all the factors studied, goals with $62.2 \%$, outside social with $53 \%$ and intention with $51.4 \%$ appear as the three most important motivating factors.

In a similar villain, the following correlation is used to show the degree of influence by the outside support on the level of goals factor.

Moreover, the results obtained from qualitative data (interviews) enhance the quantitative data and depict a clear image about students' perceptions concerning English language learning. Respondents of this study gave more explanation and illustration to the meaning of the outside social factor. According to their views, the latest progressing occurred on the general economic situation has more significant influence as a social motivation factor than their parents and other family members. Due to the security and stability in the Kurdistan region, where the Kurdish students are from, foreign companies and organizations have established businesses and organizations, which are in need of fluent English speakers, interpreters and translators. The perception of the external demand motivates the students to learn English. In such a situation, students' goals are directly connected with their intentions to learn English. The reason goals contributes the largest weight in motivating the students could be due to the fact that English is commonly used in many areas of work, and the students reason it 
important to learn the language for success in their future career. Along the same line, the same students perceive English as a global language, and perceive proficiency in the language important to broaden their access to and interaction with the world. Connected to this is the outside social factor that appears as a significant contributor to motivation for Kurdish students. In fact, all the motivating factors for Kurdish students are to some degree interconnected and the future studies should explore this joint contribution. The Figure 1 also shows that Classroom Interaction contributes the least weight, which could be due to the fact that it is more of a pedagogic strategy to encourage students to practice English than as a motivator for students to learn English.

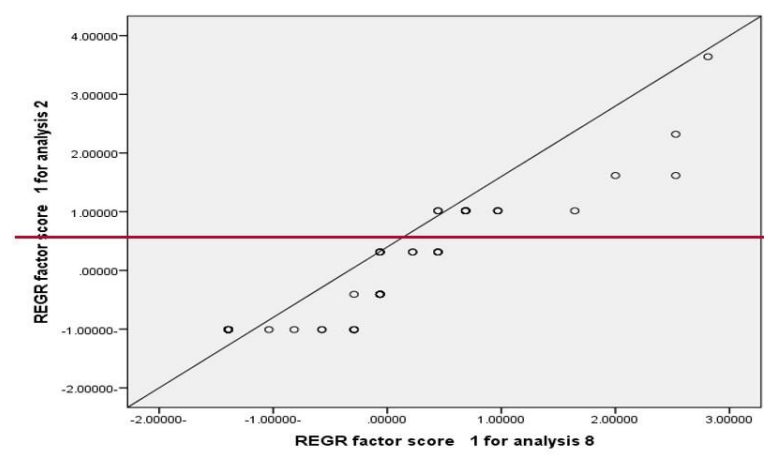

Figure 2. Correlation Diagram of Parallel significance between outside Support and Goals Factors Motivating Kurdish Students to Learn English

Moreover, the results obtained from qualitative data (interviews) enhance the quantitative data and depict a clear image about students' perceptions concerning English language learning. Respondents of this study gave more explanation and illustration to the meaning of the outside social factor. According to their views, the latest progressing occurred on the general economic situation has more significant influence as a social motivation factor than their parents and other family members. Due to the security and stability in the Kurdistan region, where the Kurdish students are from, foreign companies and organizations have established businesses and organizations, which are in need of fluent English speakers, interpreters and translators. The perception of the external demand motivates the students to learn English. In such a situation, students' goals are directly connected with their intentions to learn English. The reason why these goals contribute efficiently in motivating the students could be due to the fact that English is commonly used in many areas of work, and the students became aware of its significant importance in their future career. Along the same line, the same students perceive English as a global language, and perceive proficiency in the language as a key factor to broaden their access and interact with the world. Thus, the outside social factor appears as a significant contributor to motivate Kurdish students. In fact, all the motivating factors for Kurdish students are to some degree interconnected and the future studies should explore this joint contribution. The Figure 1 also shows that Classroom Interaction contributes the least weight, which could be due to the fact that it is more of a pedagogic strategy to encourage students to practice English than as a motivator for students to learn English.

\section{Conclusion}

Recently and in the light of education process, language learning witnessed an important turning point since it has been changed from tools of communication into required qualifications of work; particularly, new systems of labor with services and creativity (Saarikivi and Marten 2012). This study examined the factors influencing students' motivation level and it shed the light more on the motivation component of outside social support and its effect on other factors. The findings of both quantitative and qualitative data revealed that the motivation to learn English is not dominated by a single factor. However, factors of goals, outside social, and intention appear as the three most important motivating factors. Moreover, the results of the current study also showed a significant correlation between the outside social factor which and students' goals which contribute the largest weight in motivating them. Thus, students' goals are directly connected with their intentions to learn English. In sum up, the new generation in Iraqi Kurdistan region is extremely encouraged to get more competent status in society; namely business world. They think that improving their English language level is considered as a worthy qualification to acquire this status.

\section{References}

Bahous, R., Bacha, N. N., \& Nabhani, M. (2011). Motivating students in the EFL classroom: A Case Study of 
Perspectives. English Language Teaching, 4(3), 33-43.

Carroll, J. B. (1981). Conscious and automatic processes in language learning. Canadian Modern Language Review, 37, 462-74.

Cheng, H. F., \& Dörnyei, Z. (2007). The use of motivational strategies in language instruction: The case of EFL teaching in Taiwan. Innovation in Language Learning and Teaching, 1, 153-174.

Chien, C. Y., \& Young, K. (2008). The centrality of textbooks in teachers' work: perceptions and use of textbooks in a Hong Kong Primary School. The Asia-Pacific Education Researcher, 16(2).

Clément, R. (1980). Ethnicity, contact and communicative competence in a second language. En Giles, H. Robinson, W. P. y Smith, P. M. (Eds.): Language: Social Psychological Perspectives. Oxford: Pergamon.

Crookes, G., \& Schmidt, R. W. (1991). Motivation: Reopening the research agenda. Language Learning, 41, 469-512.

Crystal, D. (2003). English as a Global Language. Second Edition. Cambridge University Press.

Dörnyei, Z. (1990). Conceptualizing Motivation in Foreign Language Learning. Language Learning, 40(1), 45-78.

Dornyei, Z. (1994). Motivation and Motivating in the Foreign Language Classroom. The Modern Language Journal, 78(3), 273.

Hashimoto, Y. (2002). Motivation and willingness to communicate as predictors of reported L2 use: The Japanese ESL context.

Keong, Y. C., \& Mussa, I. H. (2015). Academic Writing Difficulties of Iraqi Postgraduate Students in Malaysia. International Journal of Education and Research, 3(6), 25-34.

Kirova, S., Petkovska, B., \& Koceva, D. (2012). Investigation of Motivation and Anxiety in Macedonia While Learning English as a Second/Foreign Language. Procedia-Social and Behavioral Sciences, 46, 3477-3481.

Krashen, S. D. (1982). Principles and practice in second language acquisition. Oxford: Pergamon.

Lee, S. Y. (2005). Facilitating and inhibiting factors in English as a foreign language writing performance: A model testing with structural equation. Language Learning, 55(2), 335-374.

Noels, K. A. (2001). Learning Spanish as a second language: Learners' orientations and perceptions of their teachers' communication style. Language Learning, 51, 107-144.

Pardo, A. N. \& Téllez, M. A. (2009). ELT Materials: The Key to Fostering Effective Teaching and Learning Settings. Profile Issues in Teachers' Professional Development, 11(2), 171-186.

Phan, H. T. T. (2010). Factors affecting the motivation of Vietnamese technical English majors in the English studies. Unpublished doctoral dissertation, University of Otago.

Rabab'ah, G. (2001). Communication Problems Facing Arab Learners of English. Journal of Language \& Learning, 3(1), 180-197.

Saarikivi, Jane., \& Marten, H. F. (2012). Introduction to the Special Issue: Political and Economic Obstacles of Minority Language Maintenance. Journal on Ethnopolitics and Minority Issues in Europe, 11(1), 1-16.

Schmidt, R., Boraie, D., \& Kassabgy, O. (1996). Foreign Language Motivation: Internal Structure and External Connections. In R. Oxford (Ed.), Language learning motivation: Pathways to the new century (pp. 9-70). Honolulu, HI: University of Hawaii Press.

Schuman, J. H. (1978). The acculturation model for second language acquisition. In R. Gingras (Ed.) Second language acquisition and foreign language teaching (pp. 27-50). Arlington V.A: Center for Applied Linguistics.

Vatankhah, M., \& Tanbakooei N. (2014). The Role of Social Support on Intrinsic and Extrinsic Motivation among Iranian EFL Learners. Procedia-Social and Behavioral Science, 98(2014), 1912-1918.

Williams, K. C., \& Williams, C. C. (2011). Five key ingredients for improving student motivation. Research in Higher Education Journal, 12, 1-23.

\section{Copyrights}

Copyright for this article is retained by the author(s), with first publication rights granted to the journal.

This is an open-access article distributed under the terms and conditions of the Creative Commons Attribution license (http://creativecommons.org/licenses/by/4.0/). 